\title{
The Blue Cross Blue Shield of Michigan Cardiovascular Consortium (BMC2) Collaborative Quality Improvement Initiative in Percutaneous Coronary Interventions
}

\author{
MAURO MOSCUCCI, M.D.,* DAVID SHARE, M.D., M.P.H., $†$ EVA KLINE-ROGERS, R.N., M.S.,* \\ MICHAEL O’DONNELL, M.D., A ANN MAXWELL-EWARD, PH.D.,§ WILLIAM L. MEENGS, M.D.,\| \\ VIVIAN L. CLARK, M.D.,\# PHILLIP KRAFT, M.D.,\# ANTHONY C. DE FRANCO, M.D.,** \\ JAMES L. CHAMBERS, M.D., ${ }^{* *}$ KIRIT PATEL, M.D., †† JOHN G. MCGINNITY, M.S., P.A.C., $\ddagger \ddagger$ and \\ Kim A. EaGle, M.D.,* on behalf of Blue Cross Blue Shield of Michigan Cardiovascular Consortium
}

(BMC2)

From the *University of Michigan, Division of Cardiology, Blue Cross Blue Shield of Michigan Cardiovascular Consortium Coordinating Center, Ann Arbor; + Blue Cross Blue Shield Center for Health Care Quality, Detroit; $¥$ St. Joseph Mercy Hospital, Ann Arbor; §Spectrum Health, Grand Rapids; |Northern Michigan Hospital, Petoskey; \#Henry Ford Hospital, Detroit; **McLaren Regional Medical Center, Flint; ††St. Joseph Hospital, Pontiac; ¥ Harper Hospital, Detroit, Michigan

\begin{abstract}
The past decade has been characterized by increased scrutiny of outcomes of surgical and percutaneous coronary interventions (PCIs). This increased scrutiny has led to the development of regional, state, and national databases for outcome assessment and for public reporting. This report describes the initial development of a regional, collaborative, cardiovascular consortium and the progress made so far by this collaborative group. In 1997, a group of hospitals in the state Michigan agreed to create a regional collaborative consortium for the development of a quality improvement program in interventional cardiology. The project included the creation of a comprehensive database of PCIs to be used for risk assessment, feedback on absolute and risk-adjusted outcomes, and sharing of information. To date, information from nearly 20,000 PCIs have been collected. A risk prediction tool for death in the hospital and additional risk prediction tools for other outcomes have been developed from the data collected, and are currently used by the participating centers for risk assessment and for quality improvement. As the project enters into year 5, the participating centers are deeply engaged in the quality improvement phase, and expansion to a total of 17 hospitals with active $P C I$ programs is in process. In conclusion, the Blue Cross Blue Shield of Michigan Cardiovascular Consortium is an example of a regional collaborative effort to assess and improve quality of care and outcomes that overcome the barriers of traditional market and academic competition. (J Interven Cardiol 2002;15:381-386)
\end{abstract}

\section{Introduction}

Since its initial introduction in 1977 by Gruentzig, ${ }^{1}$ advancements in catheter technology and improved operator techniques have resulted in a continuous

Supported by a grant from the Blue Cross Blue Shield of Michigan Foundation, Detroit, Michigan.

Address for reprints: Mauro Moscucci M.D., University of Michigan Medical Center, Taubman 3910, 1500 East Medical Center Dr., Ann Arbor, MI 48109-0022. Fax: (313) 936-5626; e-mail: moscucci@umich.edu growth of percutaneous transluminal coronary angioplasty (PTCA), with initial success rates $>90 \%$ and major complication rates $<5 \% .^{2,3}$ The approval of new devices for coronary interventions, and in particular of coronary stents, has further expanded the capabilities of percutaneous coronary interventions (PCIs). Indeed, it was estimated that in the year 1994, > 400,000 PTCAs were performed in the United States, ${ }^{4}$ with PTCA surpassing coronary artery bypass surgery as a primary treatment for coronary artery disease. More recent estimates suggest $>600,000$ procedures were performed in the United States in $1998 .^{5}$ 
While the value of PTCA as an alternative to coronary artery bypass surgery and to medical treatment for symptomatic patients with coronary artery disease has been well documented in multiple studies, ${ }^{6-9}$ the procedure is associated with a small, though not insignificant risk of morbidity and mortality, and with high costs related to equipment use, professional fees, and need for hospitalization. Variation in the outcomes of PCIs among different operators and centers may depend on multiple factors including the characteristics of the patient population treated (i.e., sicker patients are more likely to have worse outcomes), ${ }^{10,11}$ operators' skills, ${ }^{12-14}$ and procedure and postprocedure variables. A better understanding of how these factors interact can lead to a "risk-adjusted" comparison of the results of different operators and centers, and may foster improvement in the quality of care delivered through the implementation of practice guidelines, critical pathways, and "best practice strategies."

With a rapidly evolving field like interventional cardiology, single centers will not have adequate volume to quickly assess the effect of new modalities on patient outcomes in a timely fashion, or to assess the relationship between risk factors and rare complications with an adequate statistical power. In addition, without the ability to benchmark with other institutions, it will be difficult if not impossible to assess the effect of practice variations on outcomes. The objective of the project was to develop a regional multicenter $\mathrm{PCI}$ registry for the development and validation of risk-adjustment models for fatal and nonfatal outcomes of PCIs, and to develop a continuous quality improvement (CQI) program by which institutions participating in this project could be provided with feedback on their absolute and risk-adjusted outcomes, on resource use, and with the opportunity to identify potentially correctable factors associated with worse outcomes. This article describes the initial development of the authors regional, collaborative, cardiovascular consortium and the progress made so far by this collaborative group.

\section{Development of the Consortium}

In July 1996, 16 hospitals in the state of Michigan were invited to participate in a regional cardiovascular consortium. The goals of the project were to develop risk-adjustment models for fatal and nonfatal outcomes of PCIs, to analyze practice variation in PCIs, to provide feedback to individual operators and institu- tions on absolute and risk-adjusted outcomes, to develop evidence-based standardized patient care guidelines, and to improve the quality of care of patients undergoing PCIs by sharing of information and a CQI process. Nine centers agreed to participate in the consortium. A common data collection form and a standard set of definitions were developed, and a pilot 1month data collection phase begun in July of 1997. After the pilot data collection the data form was further refined. The full data collection phase began in December 1997 and it has been ongoing since then. As of March 2001, data on $>19,000$ consecutive procedures have been collected. Of the nine initial centers, three centers did not enter into the second phase of the study because of lack of resources for the data collection. Two of these three centers reentered in the consortium during the third year (Fig. 1).

\section{Structure of the Consortium}

The Blue Cross Blue Shield of Michigan Cardiovascular Consortium (BMC2) includes academic and nonacademic centers in the state of Michigan that are part of the Blue Cross Blue Shield of Michigan Cardiovascular Centers of Excellence Network. The initial proposal to include the Cardiac Centers of Excellence was felt to have added value because all institutions taking part in the Centers of Excellence Network had initiated internal efforts toward a better understanding of factors affecting outcomes and quality. Thus, it was felt that a collaborative effort between these centers could lead to a more rapid and accurate collection of meaningful data, and to more rapid and widespread understanding of and improvements in practice. ${ }^{15}$

The current structure of BMC2 includes an executive committee (a physician and an hospital administrator representative from each site), a working group (physician, nurse coordinator, and administrator from each site), and a writing committee (one physician representative from each site). The BMC2 Working Group currently meets two to three times per year to discuss the progress of the registry, resolve any issues with data collection or validation, and discuss findings of the registry. The role of the writing committee is to oversee any issue pertaining to in-depth analysis of the data and the reporting and publication in peer-reviewed forums of the findings of the collaborative project. Participation in the consortium is currently voluntary. 


\section{BMC2}

Participating

Hospitals

Since

Inception of

BMC2

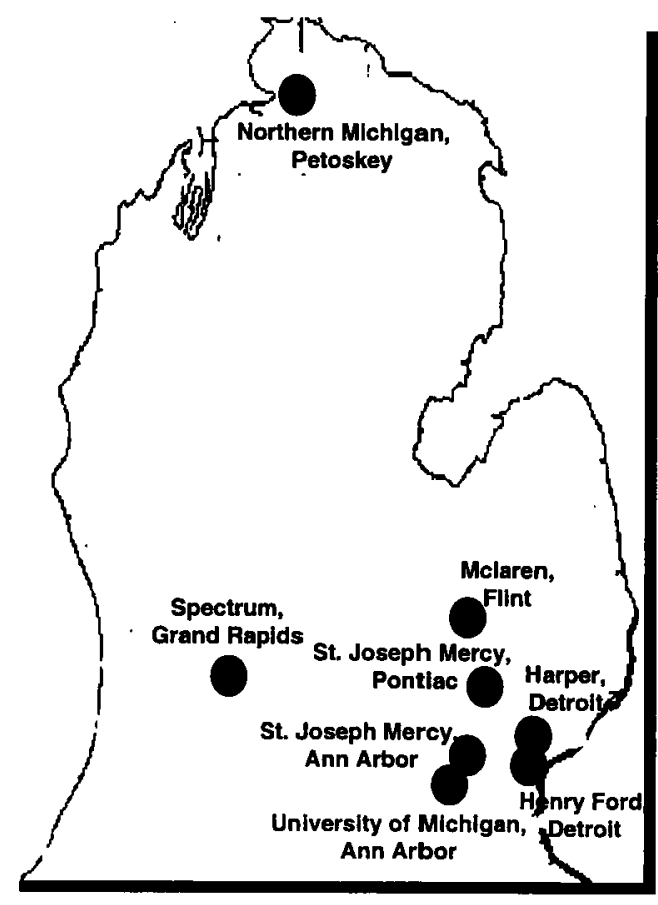

Figure 1. Map of the state of Michigan with name and geographic location of participating hospitals.

\section{Quarterly Reports}

A nine-page report for individual operators and institutions is prepared by the coordinating center every 3 months and mailed to the participating hospitals. The report includes comorbidities, resource use, indication for the procedure, procedural variables, and outcome variables. The report has three columns. The first column has individual operator summary statistics, the second column has institution summary statistics, and the third column has summary statistics from the consortium (Fig. 2). This report allows individual operators to "benchmark" their practice with their institution and with the consortium. A summary report with aggregate data by calendar year is mailed at the end of the year. The reports are currently used by the participating centers for morbidity and mortality conferences, internal review, reporting to other agencies, and to guide internal CQI activities. Because of confidentiality issues, the reports do not include direct physician or institution identifiers. Each center has electronic access to all of its own data for internal analysis and trend reporting.

\section{Data Collection}

The data collection process and data quality assurance efforts are described in detail elsewhere. In brief, each center has a dedicated data collection person. A data form is compiled for each procedure. Data quality and the inclusion of consecutive procedures is assured by site visits, ad hoc queries, random chart review, and a series of diagnostic routines included in the database. This process assures data integrity, accuracy, and completeness, which are vital to the clinically detailed, rigorous analyses performed, and it is currently not matched in global and national cardiac procedure databases.

\section{Quality Improvement Phase}

The ultimate goal of this collaborative effort is to improve the quality of care of patients undergoing PCIs. It is important to underscore that quality improvement does not imply poor baseline quality of care, but it rather implies that the identification of pre- 
$\underline{B M C}^{2}$

Blue Cross Blue Shield of Michigan

$03 / 26 / 2001$

Cardiovascular Consortium

Patient Demographics Report (sample)

Hospital Code: 99

Physician's ID: 9999

Patient Variable

Collaborative

Hospital

Physician

Patients Enrolled

$n=492$

$n=45$

$n=10$

Average Age

Gender: (\# + \% Males)

$\begin{array}{rr}63.5 & +/-12.2 \\ 330 & 67.1 \% \\ 345 & 70.1 \%\end{array}$

$64.1+1-12.8$

$30 \quad 66.7 \%$

Hypertension

$345 \quad 70.1 \%$

Dlabetes

$122 \quad 24.8 \%$

$32 \quad 71.1 \%$

$\mathrm{Hx}$ CHF

$61 \quad 12.4 \%$

COPD

CVATIA

$51 \quad 10.4 \%$

$44 \quad 8.8 \%$

Hx Cardlac Arrest

Prev MI:

Prev PTCA

Prev CABG (>0)

$8 \quad 1.6 \%$

$148 \quad 30.1 \%$

$176 \quad 35.8 \%$

$90 \quad 18.3 \%$

$9 \quad 20.0 \%$

$8 \quad 17.8 \%$

$2 \quad 4.4 \%$

$4 \quad 8.9 \%$

$24.4 \%$

$11 \quad 24.4 \%$

$12 \quad 26.7 \%$

$8 \quad 17.8 \%$

$\begin{array}{rr}63.8 & +1-13.1 \\ 9 & 90.0 \% \\ 7 & 70.0 \% \\ 1 & 10.0 \% \\ 1 & 10.0 \% \\ 0 & 0.0 \% \\ 1 & 10.0 \% \\ 1 & 10.0 \% \\ 4 & 40.0 \% \\ 4 & 40.0 \% \\ 5 & 50.0 \%\end{array}$

Confidential:

For Quality Assurance Work ONLY

This report covers the time period from: $07 / 01 / 2000$ to: $08 / 01 / 2000$

Figure 2. Representative sample of quarterly report (baseline demographic table). 
viously unknown risk factors or practice variations related to adverse events can result in modification in practice leading to improved outcomes. The process followed is similar to the process that was followed by the Northern New England Cardiovascular Study Group for its quality improvement initiative in coronary artery bypass surgery. ${ }^{16}$ In their study, a preintervention period of data collection for patients undergoing coronary artery bypass surgery was followed by feedback on outcome data, training in quality improvement, and site visits. During the postintervention period, there was a $24 \%$ reduction in hospital mortality $(P=0.001)$. The reduction in hospital mortality was consistent among patient subgroups and was temporally associated with the intervention.

In the present study, participating institutions are provided feedback on their absolute and risk-adjusted outcomes. New findings pertaining to outcome analysis are shared with the participating centers during quarterly meetings and through a newsletter. The group has so far identified significant practice variations in use of resources and variation in some of the outcome variables. These variations are currently the focus of the quality improvement phase. A risk-adjustment model for death in the hospital and a risk prediction rule for individual patients have been developed. This bedside risk prediction tool allows an informed discussion with the patients and with their families regarding prognosis before and after percutaneous revascularization procedures. ${ }^{17}$ Additional risk prediction rules for other fatal and nonfatal complications are currently under development. For example, contrastinduced nephropathy requiring dialysis is a rare complication of coronary revascularization procedures that is associated with a high in-hospital mortality rate. A risk prediction rule that allows the identification of patients who might be at higher risk of developing this complication has been developed and it is currently used by participating physicians. Identification of patients at increased risk should lead to modifications in procedural strategies aimed toward the prevention of this complication (e.g., maximizing hydration before the procedure, minimizing of the amount of contrast administered through special angiographic techniques, precise calculation of maximal allowable contrast dose for individual patients). The same process has been applied to other complications like bleeding complications, transfusion requirement, and emergency or urgent coronary artery bypass grafting (CABG) following coronary interventions.
Formal exposure to the CQI method supports the development and application of guidelines and pathways, and provides the opportunity to identify potentially correctable variables and to reassess outcomes during a postintervention phase. Assessment of appropriateness of procedures performed will be part of this quality improvement process.

The quality improvement process includes site visits for comparison of the care process and for exchange of information. During these site visits, the host is instructed to continue with "business as usual" while the guest is instructed to "compare with home." Three site visits have been completed so far. These site visits are in addition to the routine site visits that are performed twice a year by the clinical coordinator for data quality assurance and for assessment of data integrity. They are generating additional information on variations in care processes and a true spirit of collaboration among the participating hospitals, all of which serves as a stimulus to rapid cycle quality improvement.

\section{Future Developments}

As the project moves into the year 5, the Blue Cross Blue Shield of Michigan PPO intends to expand participation in the BMC2 project to all Blue Cross Blue Shield of Michigan Cardiac Centers of Excellence. This expansion will occur through funding of data collection at the participating institutions by Blue Cross Blue Shield of Michigan. When this expansion is completed, the project will include up to 17 hospitals, making it a compelling and unique example of collaborative efforts between payers and providers designed to assess outcomes, correlate them with care processes, and use the learning achieved to guide quality improvement.

\section{Conclusions}

The past decade has been characterized by increased scrutiny of outcomes of surgical and percutaneous cardiovascular procedures. This increased scrutiny has led to the development of regional, state, and national databases for outcome assessment and for public reporting. The BMC2 is an example of a regional collaborative effort to assess and improve quality of care and outcomes which overcomes the barriers of traditional market and academic competition. Based on the 
progress achieved by the collaborative group so far, it is anticipated that this effort will result in improved outcomes and decreased costs of PCIs in the state of Michigan.

\section{Appendix}

BMC2 Hospitals and Working Group Members. University of Michigan Health System in Ann Arbor (BMC2 Coordinating Center): Kim A. Eagle, M.D., F.A.C.C., Mauro Moscucci, M.D., Eva Kline-Rogers, M.S., R.N., Diane Bondie, B.S., Bruce Rogers B.S., Jeanna Cooper, M.S.; Blue Cross Blue Shield of Michigan: David Share, M.D.; Northern Michigan Hospitals in Petoskey: William Meengs, M.D., Robert Sloan, M.B.A., Cindy Bodurka, R.N.; Spectrum Health Downtown in Grand Rapids: William McNamara, M.D., Ann Maxwell-Eward, Ph.D., Sherri Kanten, R.N., Renee Stamper, J.D.; McLaren Regional Medical Center in Flint: Anthony DeFranco, M.D., F.A.C.C., James Chambers, D.O., Cathy Fisk, R.N., Leisa Pertler, R.N., Stacey Somsky, R.N.; St. Joseph Mercy Hospital in Ann Arbor: Michael O'Donnell, M.D., Patricia Wren, R.N.; St. Joseph Mercy Hospital in Pontiac: Kirit Patel, M.D., Susan Wright, R.N., Bethany Smith, R.N.; Harper Hospital in Detroit: John McGinnity, M.S., P.A.-C., Cathy June, R.N.; Henry Ford Hospital in Detroit: Vivian L. Clark, M.D., Phillip Kraft, M.D., Laurel Dvorak, R.N., Kelly Ryan, R.N., Margaret Fox, R.N., Cathy Lucarelli, R.N.

\section{References}

1. Gruentzig AR. Transluminal dilatation of coronary artery stenoses. Lancet 1978;1:263.

2. Baim DS. A symposium: Interventional cardiology-1987. Am J Cardiol 1988;61: $1 \mathrm{~g}-117 \mathrm{~g}$

3. Detre K, Holubkov R, Kelsey S, et al. Percutaneous translumi- nal coronary angioplasty in 1985-1986 and 1977-1981. The National Heart, Lung and Blood Institute Registry. N Engl J Med 1988:318:265-270.

4. USCI. Division of CR Bard, Inc. Industry assessment 1994. Internal publication.

5. CDCNCHS and the American Medical Association statistical data.

6. Gruentzig AR, King SB III, Schlumpf M, et al. Long-term follow-up after percutaneous transluminal coronary angioplasty. The early Zurich experience. N Engl J Med 1987;316:11271132.

7. Parisi AF, Folland ED, Hartigan P. A comparison of angioplasty with medical therapy in the treatment of single vessel coronary disease. Veterans Affairs ACME Investigators. N Engl J Med 1992;326:10-16.

8. Goy JJ, Eeckhout E, Burnand B, et al. Coronary angioplasty versus left internal mammary artery grafting for isolated proximal left anterior descending artery stenosis. Lancet 1994;343:1449-1453.

9. Coronary angioplasty versus coronary artery bypass surgery: The Randomized Intervention Treatment of Angina (RITA) trial. Lancet 1993; 341:573-580.

10. O'Connor GT, Malenka DJ, Quinton $H$, et al., for the Northern New England Cardiovascular Disease Study Group. Multivariate prediction of in-hospital death following percutaneous coronary interventions in 1994-1996. J Am Coll Cardiol 1999;34:681-691.

11. Moscucci M, O'Connor GT, Ellis SG, et al. Validation of risk adjustment models for in-hospital PTCA mortality on an independent data set. J Am Coll Cardiol 1999;34:692-697.

12. Hannan EL, Racz M, Ryan TJ, et al. Coronary angioplasty volume-outcome relationships for hospitals and cardiologists in New York state, 1991-1994. JAMA 1997;277:892-898.

13. Jollis JG, Peterson ED, DeLong ER, et al. The relation between the volume of coronary angioplasty practice at hospitals treating Medicare beneficiaries and short-term mortality. N Engl J Med 1994;331:1625-1629.

14. Ellis SG, Omoigui N, Bittl JA, et al. Analysis and comparison of operator specific outcomes in interventional cardiology: From a multicenter database of 4860 quality-controlled procedures. Circulation 1996;93:431-439.

15. Pine M, Berman Jl, Byrwa KJ. Forming a coronary service network on the basis of quality of care. Quality Management in Health Care 1996;4:14-23.

16. O'Connor GT, Plume SK, Olmstead EM, et al. A regional intervention to improve the hospital mortality associated with coronary artery bypass graft surgery. JAMA 1996:275:841846.

17. Moscucci M, Kline-Rogers E, Share D, et al. Simple bedside additive tool for the prediction of in-hospital mortality after percutaneous coronary interventions. Circulation 2001;104 263-268. 